\title{
N9 $0-24356$
}

THERMAL CONDUCTIVITY OF METALS

\author{
Sayyed M. Kazem \\ MET Department, Purdue University \\ West Lafayette, IN
}

\section{OBJECTIVE}

To familiarize students with steady and unsteady heat transfer by conduction and with the effect of thermal conductivity upon temperature distribution through a homogeneous substance.

Prerequisite or corequisite:

a) Physics - high school or college freshman course, with heat topic which introduces conductivity property and units.

b) Introductory discussion of concept of heat transfer in the laboratory, including a handout to give students an appropriate background.

\section{INTRODUCTION}

A knowledge of material structure and properties is a prerequisite for the selection and safe use of engineering materials by the designer. Structure, generally studied and postulated by scientists, determines properties which characterize the behavior of interacting materials, exposed to different effects. For a designer, strength and hardness are the important mechanical properties for a part to be loaded or indented by outside force. Moreover, the designer should also consider thermal properties, for parts to serve at temperatures other than as fabricated, or to perform some heat-transfer function.

For example, when a metal rod is hot worked (or heated) it exhibits three thermal effects: a) the rod absorbs heat; it expands; c) it transmits heat. Absorption of heat is characterized by the property "specific heat capacity" $c_{p}$; $i . e$. , the energy $Q$ (Joules) required to raise one unit mass $m(k g)$ by temperature change $\Delta \mathrm{T}$ of one degree $\left(\mathrm{K}^{\mathrm{O}}\right)$. Expansion is usually described by "coefficient of linear thermal expansion" ( $\alpha$ linear expansivity); i.e., fractional change in original length, $\Delta \mathrm{L} / \mathrm{L}$ per unit change in temperature $\Delta \mathrm{T}\left(\mathrm{K}^{\circ}\right)$. Heat transmission is identified mainly by thermal conductivity (k), a measure of the ease of thermal-energy transmission through a body; i.e., the rate of energy (Joules/s) in a unit thickness $\Delta x$ $(\mathrm{m})$ of unit area $A\left(\mathrm{~m}^{2}\right)$, and unit change in temperature $\Delta \mathrm{T}\left(\mathrm{K}^{\circ}\right)$.

Thermal conduction is important in modern manufacturing processes: Heat treating, die casting, plastics molding, heatsink soldering and platen heating. The two other forms of heat 
transmission (convection and radiation) may also be present but their effects are often negligible. Hence, an intuitive understanding of heat conduction is essential for materials engineers. Materials textbooks, handbooks, and standards (e.g., ASM Metals Handbook, CRC Physics and Chemistry Handbook, CINDAS database) give exhaustive tables of thermal properties of a myriad of engineering materials, but rarely do references describe an experiment to measure thermal conductivity.

This paper presents a simple heat conduction experiment to give insight into the concept of steady and transient heat transfer. Students can measure the temperature distribution along the heat path, learning how thermal conductivity differs for different materials. After presenting the theoretical backgrounds, test equipment and procedure will be covered, data sheet exhibited, sample calculations outlined, graphs plotted and some concluding remarks made.

\section{THEORY}

Heat flows naturally from a high-temperature point to a lowtemperature point. Consider a homogeneous metal rod (mass $m$, cross-section $A$, length $L$ ) with perfectly insulated perimeter and five equally spaced thermocouples embedded to the center of the rod (Figure 1). Assume the rod is initially at temperature $\mathrm{Ti}$. If the upper face stays at temperature $T i$, while the lower face is suddenly subjected to a higher constant temperature $T_{h}$ heat source, the molecules on that face start absorbing thermal energy, vibrating at higher velocity and passing some of their energy to adjacent molecules in the metal. Furthermore, "free electrons" start to drift and transfer "heat" along the rod.

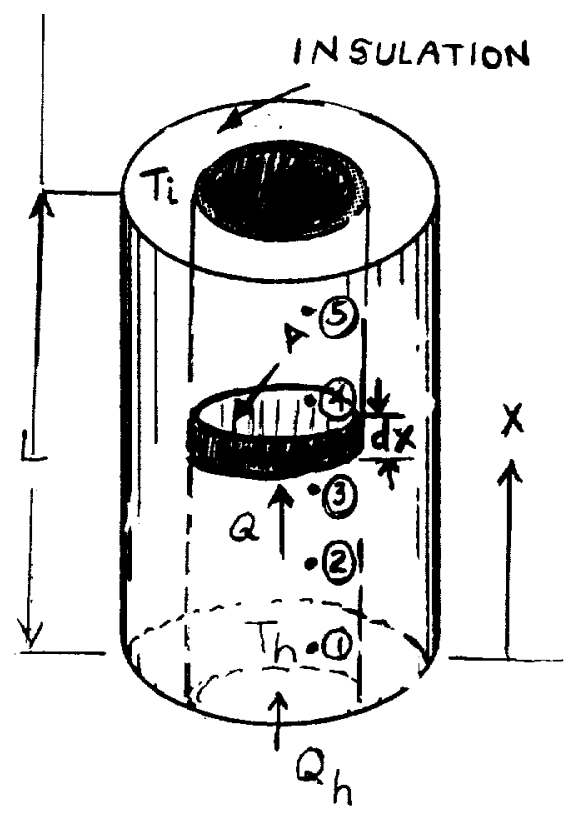

As time passes, some of the "thermal energy" flows continuously in the $x$-direction. Some of the thermal energy is partially stored (absorbed) in the bar, continuously increasing its "temperature" along the bar; and if imposed conditions on the faces are maintained, heat flows up the rod, and temperature at each part will always be lower than a preceding point.

Now, consider a disk element (thickness $d x$ ) across which the temperature change is $d T$ and the heat flow-rate is $Q$. According to Fourier's law of heat conduction, the amount of heat transferred is 


$$
Q=-k A(d T / d x)
$$

where, $d T / d x$ is "temperature gradient", the temperature drop per unit length; $k$ is "thermal conductivity" of the material. The negative sign indicates heat flowing towards decreasing temperature.

The rate of energy stored $\mathrm{dE}$ in the element is given by $\mathrm{dE}=\mathrm{m} \mathrm{cp} d \mathrm{~T} / \mathrm{dt}$,

where, cp is "specific heat capacity", and $t$ is "time".

The condition where the temperature $T$ at a position $(x)$ is continuously changing with time, is called unsteady (transient) state.

If imposed conditions are maintained long enough, there comes a time after which the temperature at any given point does not change with time, no more energy is being stored in the rod; hence the rate of heat entering the lower face will equal the rate leaving the upper face, or $\mathrm{dE}=0$. This is called "steady state". For a homogeneous substance with constant thermal conductivity the steady state rate of heat flow (Q) could be written as

$$
Q=-\mathrm{kA} \Delta \mathrm{T} / \Delta \mathrm{x}
$$

where $\Delta$ refers to finite change.

Consider several different metal rods with the same dimensions and the same steady state $Q$. If $\mathrm{k}$ of one sample is known, one can determine $k$ for any other sample: Let the samples be numbered $1,2,3 \ldots$

$$
\begin{aligned}
\text { Then, } & Q=-k_{1} A(\Delta T / \Delta x)_{1} \\
& Q=-k_{2} A(\Delta T / \Delta x)_{2} \\
\text { Hence, } & \left.k_{2}=\frac{(\Delta T / \Delta x}{K_{1}}\right)_{1}
\end{aligned}
$$

Temperature gradient $(\Delta T / \Delta x)$ is found by plotting measurements of $T$ vs $x$, which also gives the "temperature distribution" showing temperature at any point on the bar.

Good electrical conductors are good thermal conductors, as indicated by the "Widemann-Franz" relationship, for a given

temperature: $k$ is proportional to $\sigma$, or

$$
\mathbf{k}=\mathbf{L T} \sigma
$$

where, $L$ is a published constant.

For two different metals at the same temperature, using the above relationship, one may write

$$
\mathrm{k}_{2} / \mathrm{k}_{1}=\sigma_{2} / \sigma_{1}
$$

If the two $\sigma$ or their ratio $\sigma_{2} / \sigma_{1}$ and one thermal conductivity are known or estimated, the other thermal conductivity can be evaluated. 
EXPERIMENTATION

A. Test Equipment

The specimens:

aluminum alloy

(6061 T6), brass

(yellow), and steel

(cold rolled) had

thermo-couples

connected at dis-

tances of $0.5,3.0$,

$5.5,8.0$, and $10.5 \mathrm{~cm}$

from the bottom

of the specimens

which were wired

into an Omega Trendi-

cator that reads

temperatures at

each point.

The specimens

were mounted in a

bucket and surrounded

with insulation leaving

only the top of the

specimen exposed and the bottom touching the bucket. The bucket was then placed on a Thermolyne corporation hot plate which was preheated to $200^{\circ} \mathrm{C}$. A stopwatch was used for timing the readings.

\section{B. TEST PROCEDURE}

The heater (hot plate) was turned on, set at about the 400 watt mark $\left(\sim 200^{\circ} \mathrm{C}\right)$ and left to achieve steady state. Then, while the bucket of specimens was placed on the hot plate, the stop watch was started. The first 5 runs of temperatures vs time were read after every 2 minutes and afterwards every 5 minutes till steady state was achieved or approached. Then, the hot plate and thermocouple indicator were turned off. The whole experiment took 60 minutes.

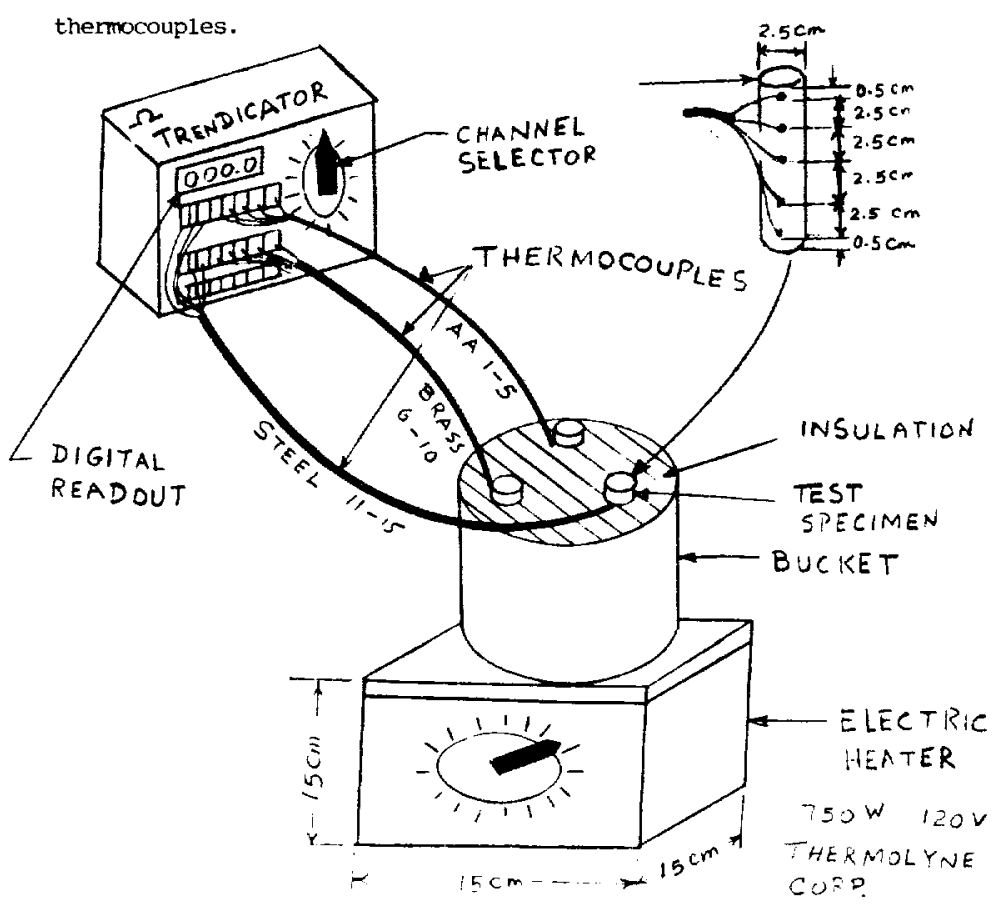

FIGURE 1 
EVALUATIONS:

1. Graph temperature $T$ versus time $t$ for the middle point of each specimen on the same sheet of graph paper. Label graphs completely and identify the transient and steady state regions.

Answer: $\quad$ See Figure 3

2. On the same sheet, graph the temperature versus distance (position) along the bar for the steady state (last set of readings), and determine the temperature gradient for each sample.

Answer: See Figure 4 for the graph

$$
\begin{aligned}
& (\Delta \mathrm{T} / \Delta \mathrm{x})_{\mathrm{AA}}=-1.133 \mathrm{c}^{\circ} / \mathrm{cm}=-113.3 \mathrm{c}^{0} / \mathrm{m} \\
& (\Delta \mathrm{T} / \Delta \mathrm{x})_{\mathrm{Br}}=-1.808 \mathrm{c}^{\circ} / \mathrm{cm}=-180.8 \mathrm{c}^{0} / \mathrm{m} \\
& (\Delta \mathrm{T} / \Delta \mathrm{x})_{\mathrm{St}}=-2.33 \mathrm{c}^{\circ} / \mathrm{cm}=-233 \mathrm{c}^{0} / \mathrm{m}
\end{aligned}
$$

3. Estimate the thermal conductivity ratios $k_{\mathrm{Br}} / \mathrm{k}_{\mathrm{AA}} \mathrm{kst} / \mathrm{kAA}$

\section{Answer:}

From Equation (6) $\mathrm{k}_{\mathrm{Br}} / \mathrm{kAA}=\frac{\left(\Delta_{\mathrm{T}} / \Delta \mathrm{x}\right) \mathrm{AA}}{(\Delta \mathrm{T} / \Delta \mathrm{x}) \mathrm{Br}}=\frac{-1.133 \mathrm{c} / \mathrm{cm}}{-1.808 \mathrm{c} / \mathrm{cm}}=0.627$

$$
\mathrm{kst} / \mathrm{kAA}=\frac{(\Delta \mathrm{T} / \Delta \mathrm{X}) \mathrm{AA}}{(\Delta \mathrm{T} / \Delta \mathrm{x}) \mathrm{St}}=\frac{-1.133}{-2.33} \mathrm{C} / \mathrm{cm}=0.486
$$

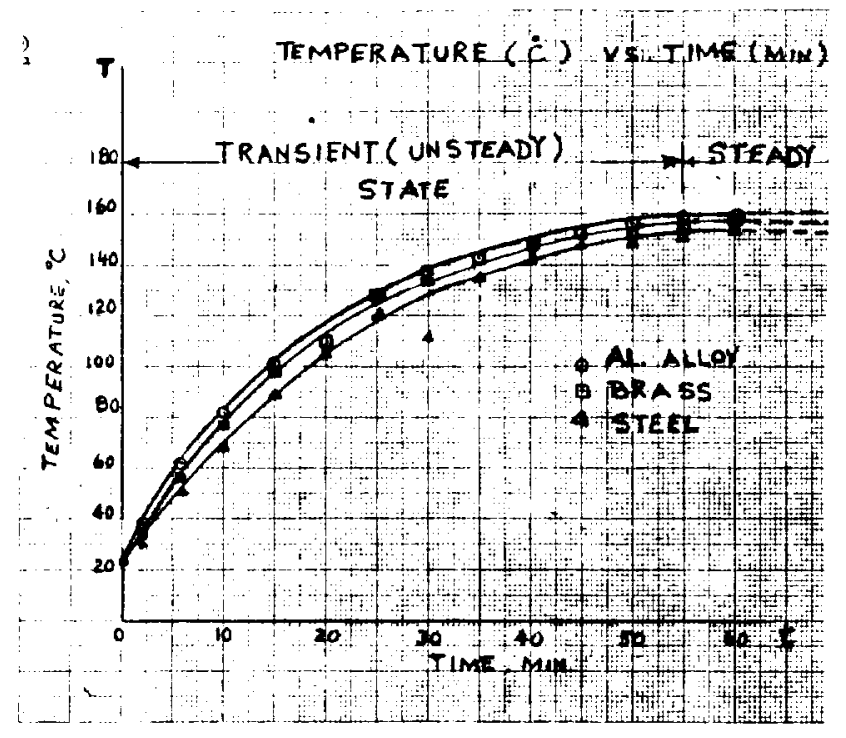

FIGURE ${ }_{3}^{\uparrow}$

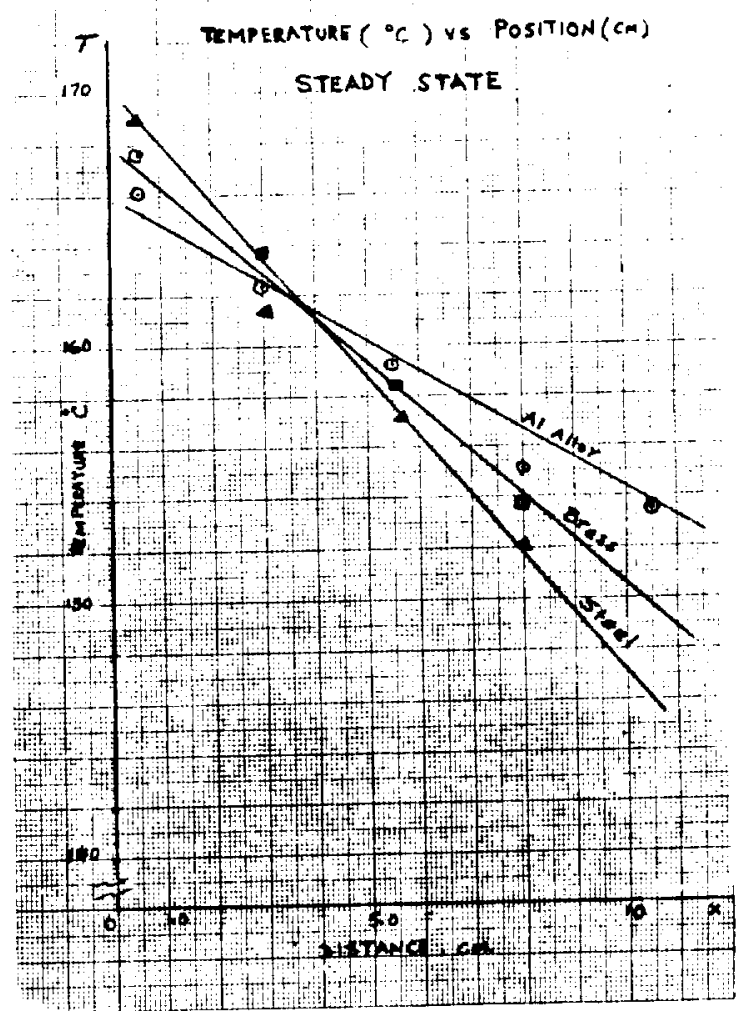


4. Compare the $k$ ratios found experimentally with the true ratios.

Answer: From the references $\mathrm{k}_{\mathrm{AA}}=168.1 \mathrm{~J} / \mathrm{s} \mathrm{mK}^{\circ}$

$$
\mathrm{k}_{\mathrm{Br}}=98.8 \mathrm{~J} / \mathrm{sm} \mathrm{K} \quad \mathrm{k}_{\mathrm{st}}=72.8 \mathrm{~J} / \mathrm{s} \mathrm{mk}
$$

Therefore,

$$
\begin{aligned}
& \left(\mathrm{k}_{\mathrm{Br}} / \mathrm{k}_{\mathrm{AA}}\right) \text { true }=0.587\left(\mathrm{k}_{\mathrm{Br}} / \mathrm{k}_{\mathrm{AA}}\right) \text { exp }=0.627 ; \cdot / \text { error }=6.7 \\
& \left(\mathrm{k}_{\mathrm{st}} / \mathrm{k}_{\mathrm{AA}}\right) \text { true }=0.433,\left(\mathrm{k}_{\mathrm{st}} / \mathrm{k}_{\mathrm{AA}}\right) \text { exp }=0.486 ; . / \text { error }=12.2
\end{aligned}
$$

5. From the references find the thermal conductivity for each specimen, determine the $\sigma$ ratios and compare them with the true $k$ ratios.

Answer:

$$
\begin{array}{llll}
\sigma_{A A}= & 0.222 & \mathrm{n}^{-1} & \mathrm{~cm}^{-1} \\
\sigma_{B r}= & 0.158 & \Omega^{-1} & \mathrm{~cm}^{-1} \\
\sigma_{S t}= & 0.034 & \Omega^{-1} & \mathrm{~cm}^{-1} \\
\frac{\sigma_{B r}}{\sigma_{A A}}=0.712 & : & \frac{\sigma_{S t}}{\sigma_{A A}}=0.150
\end{array}
$$

6. Calculate $Q / A$ for each sample using the true $k$ value and $\Delta \mathrm{T} / \Delta \mathrm{X}$

Answer:

$$
\begin{aligned}
& (Q / A)_{A A}=-k_{A A}(\Delta T / \Delta X)_{A A}=19046 \mathrm{~J} / \mathrm{sm}^{2} \\
& (Q / A)_{B \sigma}=17,863 \mathrm{~J} / \mathrm{sm}^{2},(Q / A) \mathrm{s}=16,962 \mathrm{~J} / \mathrm{sm}^{2}
\end{aligned}
$$

REMARKS

The elementary heat conduction experiment presented is designed, for associate degree technology students, in a simple manner to enhance their intuition and to clarify many confusing concepts such as temperature, thermal energy, thermal conductivity, heat, transient and steady flows. The equipment set is safe, small, portable $(10 \mathrm{~kg})$ and relatively cheap (about $\$ 1200)$ : The electric hot plate $2 \mathrm{~kg}(4.4 \mathrm{lb})$ for $\$ 175$ : the 24 channel selector and Thermocouple Digital Readout (Trendicator) $4.5 \mathrm{~kg}$ (10 1b) for about \$1000; the three metal specimens (each of 2.5 $\mathrm{cm}$ diameter and $11 \mathrm{~cm}$ length), base plate and the bucket all about $3 \mathrm{~kg}$ ( $7 \mathrm{lb}$ ) for about $\$ 25$. The experiment may take from 60 to 70 minutes. Although the hot plate surface temperature could be set from 90 to $370{ }^{\circ} \mathrm{C}$ (maximum of 750 watts) it is a good practice to work with temperatures of 180 to $200 \mathrm{C}$ (about 400 watts). Students should be reminded of safety when working with high temperatures and voltages. They may experiment in squads of 2,3 or even 4 , or the instructor may demonstrate it for the whole class. 
One part of exercises requires that the students use references for finding the true $k$ and $\sigma$ values. It is $a$ challenge.

SYMBOLS

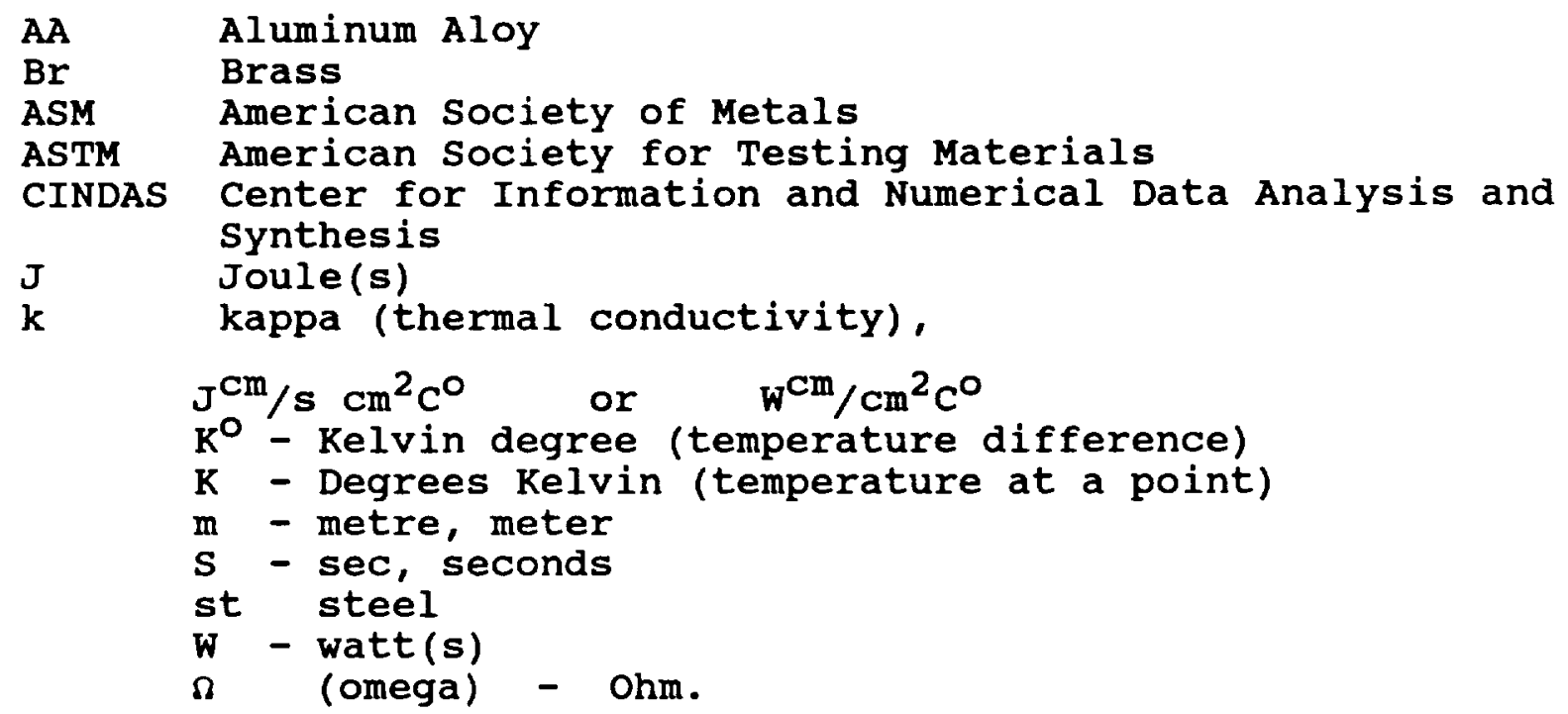

\section{REFERENCES}

Flinn, Richard A. and Trojan, Paul A., Engineering Materials and Their Applications, second Edition, Houghton Mifflin Company, Boston, MA 1981 .

Van Vlack, Lawrence H. A Textbook of Materials Technology, Addison Wesley Pub. Co., Reading, MA, 1973.

Budinski, K., Engineering Materials: Properties and Selections, 2nd Ed., Reston Pub. Inc., Reston, Virginia, 1983.

Emshousen, F.W. and Kazem, S.M. Introduction to Heat Power Laboratory Textbook, 2nd Rd., Learning System, Inc., West Lafayette, IN 47907.

American Society for Metals, Metals Handbook, 8th ed., Metals Park, Ohio.

American Society for Testing Materials (ASTMA) Designation C 177-45

Smithells, C.J. Metals Reference Book, Vol. 3, 4, 4th ed., Plenum Publishing Corp., New York, 1967.

The Aluminum Association, Aluminum Standards and Data, 1974-75.

Hodgman, C.D., et al, Ed. Handbook of Chemistry and Physics, 40th ed., CRC, Cleveland, Ohio 1959. 
